\title{
Study on the Layered and Mobile English Teaching Mode in Senior High School under the New College Entrance Examination Background

\author{
Luo Qian
}

\author{
Foreign Language College, JingChu University of Technology, Jingmen 448000, Hubei, China \\ tobabyluo@qq.com
}

Keywords: New college entrance examination, Senior high school, Layered and mobile, Teaching mode.

\begin{abstract}
The Implementation Opinions on Deepening the Implementation of the Reform of the Entrance Examination System" reforms the scheme of College Entrance enrollment on English subject, which brings unprecedented Opportunities and challenges to English teaching in senior high school. Based on the theories of "teach students in accordance with their aptitude", humanism and language input hypothesis, the layered and mobile English teaching mode has important significance for satisfying students' individual requirements on learning, improving the English teaching efficiency in senior high school and adapting the reform of the new college entrance enrollment. This document explains and demonstrates four strategies of layered and mobile English teaching mode in senior high school, which include formulating the re-composing class standards, identifying the teaching demanding, adopting suitable teaching methods, consummating testing and evaluation system.
\end{abstract}

\section{新高考背景下普通高中英语分层走班教学模式研究 \\ 罗倩}

荆楚理工学院外国语学院, 荆门 448000, 湖北, 中国

关键词：新高考; 普通高中; 分层走班; 教学模式

中文摘要: 《关于深化考试招生制度改革的实施意见》对英语科目的高考招生方案进行了重 大改革, 给高中英语教学带来了前所未有的机遇和挑战。英语分层走班教学模式以 “因材施 教” 教育学理论、“人本主义” 心理学理论和 “输入假设” 语言习得理论为基础, 对于满足 学生个性化学习的需求、提高高中英语课堂教学效率、适应新高考招生改革的需要具有重要 意义。高中英语分层走班教学模式的实施策略包括制定分层编班标准、明确分层教学目标要 求、采用合适的教学方法、完善教学评价体系四个方面。

\section{1. 引言}

国务院在2014年9月发布《关于深化考试招生制度改革的实施意见》，标志着新一轮考试 招生制度改革全面启动。《实施意见》对英语科目的高考招生方案进行了重大改革, 明确提 出“保持统一高考的语文、数学、外语科目不变, 外语科目提供两次考试机会”。新高考招生 录取制度改革给高中英语教学带来了前所未有的机遇和挑战, 促进了高中英语教学模式的创 新和变革。其中, 英语分层走班教学模式逐渐成为各地高中英语教学的新常态, 该模式在“以 人为本, 因材施教”的原则指导下, 根据学生的英语基础和学习意愿, 将同一行政班的学生分 
成不同层级, 开展有针对性的教学, 使全体学生都在原有基础上学有所得。本文从分层走班 的理论基础出发, 阐述了高中英语分层走班教学模式的重要意义, 并探索相关的实施策略, 以期为新高考背景下高中英语教学改革提供借鉴。

\section{2. 英语分层走班教学模式的理论依据}

英语分层走班教学模式的有效实施有赖于理论体系的建立与健全。总的来说, 该教学模 式的理论支撑主要来自于“因材施教”教育学理论、“人本主义”心理学理论和“输入假设”语言 习得理论，上述理论多维交互作用构成了高中英语分层走班教学模式的理论框架。

\section{1“因材施教”教育学理论}

中国古代教育家孔子首倡了“因材施教”的教育理论。他主张教育应有针对性, 考虑学生的 个性和特长, 注重扬长补短, 学有所得。其本质是根据学生的兴趣、特长、个性和志向进行 差异化教育, 最大限度的激发学生的潜能, 做到人尽其才。需要指出的是, 高中英语分层走 班教学模式的理念在“因材施教”教育思想的基础上有了新的发展。孔子当时提出的因材施教 立足于个体教学, 而现在倡导的分层教学理念则更多的强调学校集体教学。

\section{2“人本主义”心理学理论}

上世纪末, 以罗杰斯为代表的人本主义心理学提出了“以人为中心”的理念。它突出学生学 习主体的地位与作用。提倡学会适应变化、学会学习的思想。它提倡建立民主平等的师生关 系, 创造最佳的教学心理氛围。人本主义对高中英语分层走班教学模式的启示在于: 作为高 中英语教学的对象, 学生的情况千差万别, 他们的起点不同、兴趣各异, 采取的学习方式及 达到的学习效果也必定不一样。而关注人、生成人是我们一切教育的出发点和归宿, 教师对 各层级的学生应一视同仁, 教学的中心应围绕学生的学习需求而展开。

\section{3“输入假设”语言习得理论}

“输入假设”语言习得理论也称为“语言习得 $i+1$ ”理论，是由美国语言学家克拉申提出的。 克拉申认为, 语言习得的重要条件之一是语言学习者必须理解所输入的语言, 并且该语言内 容必须略高于学习者现有的知识水平。假设 $\mathrm{i}$ 为语言学习者现有的知识水平, 那么输入的内容 相对于学习者已有水平略微高一些, 即 $\mathrm{i}+1$, 才能达到最佳的学习效果。如果输入的内容太难, 变为 $i+2$, 学习者无法掌握所学内容, 极易因为挫败感而放弃学习。如果输入的内容太简单, 即 $i+0$, 学生学习时感到没有进步的余地, 无法产生学习动力, 难以达到良好的学习效果。这 一理论充分体现了高中英语分层走班教学模式循序渐进的特点。

\section{3. 英语分层走班教学模式的意义}

\section{1 满足学生个性化的学习需求}

由于不同学生的性格特征, 学习动机, 知识背景, 学习能力和英语水平存在差异, 传统的 固定班级教学难以满足学生自主选课、个性化学习的需求, 势必造成学生英语学习动力不足, 上课注意力不集中和教学效果不理想等问题。高中英语分层走班教学模式充分尊重了学生对 英语学习的不同需求, 针对不同层级的学生采用不同教学内容与教学要求, 既大大降低了“学 困生”的学习难度, 又满足了“学优生”更高的要求, 使每个层级的学生都能找到适合自己的英 语学习途径, 从而提高了学生对英语学习兴趣和主观能动性, 满足学生个性化学习需求。

\section{2 提高高中英语课堂教学效率}

传统的高中英语课堂教学由于没有对进行科学的学生英语水平摸底, 只能单纯依据学生 中考的英语成绩判断学生的英语能力, 教师对教学对象充满了未知数。在教学的过程中, 学 
生英语水平参差不齐, 为了完成统一的教学目标, 教师不得不准备几套教学方案来适应学生, 费时费力, 顾此失彼。在分层走班模式下, 同一班级的学生英语水平大致相当, 教师的教学 更有针对性, 减少了花费在已掌握英语知识的时间和精力, 同时学生对自身英语能力与预期 的学习目标有一定的认知, 在了解自身英语能力等级的基础上采取适合自身英语能力发展的 学习方法, 达到知识技能组合的最优化, 从而最大限度的避免了教学中的干扰因素, 提高了 高中英语课堂教学的效率。

\section{3 适应新高考招生改革的需要}

在传统的英语高考制度下, 应届高中毕业生只有一次英语高考机会, 因此各地高中的英语 课程都是按照行政班“齐步走”的教学组织管理方式。所有的学生采用同样的教学要求、教学 方法和教学进度进行授课。而且传统的高中英语课堂注重语言知识和技能的传授, 轻视语言 的实际运用。新的高考考试招生制度允许学生根据自己的情况多次参加英语考试, 并且注重 英语应用能力的考查, 这就促使高中英语教学在教学进度、教学方法等方面尽快做出调整, 英语分层走班教学模式尊重学生的主观能动性, 以不同的标准, 不同的进度培养学生, 适应 新高考改革的需要。

\section{4. 高中英语分层走班制教学的实施策略}

\section{1 制定分层编班标准}

分层走班是为了加强对不同层次学生的学习指导, 因此客观、合理的分班标准对整个高 中英语分层走班模式的顺利实施至关重要。一般来说, 高中英语分层的标准除了依赖学生前 一学年或某学段的成绩外, 还要根据影响教学效果的周边因素做一些细微的调整, 包括学生 的学习潜力、学习兴趣、教师评价, 特别注重参考学生申请、家长的意见, 形成灵活、动态 的分层标准。例如把学生划分 $\mathrm{A} 、 \mathrm{~B} 、 \mathrm{C}$ 三个层级, 其中 $\mathrm{A}$ 级为基础级, 适合英语基础较差和 英语学习存在困难的学生。 $\mathrm{B}$ 级为提高级, 适合英语基础和学习态度一般的学生, C级为发 展级，由英语基础扎实的学生组成。同时分层走班中的“分层”是着眼于人在发展过程中的个 别差异，并把个体差异看作资源来开发。学生是有差异的，更是发展的。因此“分层”应该是 动态的。根据学生的学习状态, 在一段时间的英语学习后, 退出原有的学习层次并向上下层 级流动。例如在两个学期的英语课程学习后还进行 $\mathrm{A} 、 \mathrm{~B} 、 \mathrm{C}$ 三个层级间流动性测试。对于有 明显提高的学生可以适时令其进入上一层级, 对于跟班困难的学生则鼓励其加入低层级的班 级。不同层级的流通过程给学生带来危机感的同时也促使学生积极进取、主动学习, 从而大 大激发其求知积极性, 有利于形成互帮、互助、互赶的学风。

\section{2 明确分层教学目标要求}

在各层级人员基本确定后, 下一步是制定相应的分层走班教学目标, 以便有效地指导教 学。分层走班教学目标的制定应以学生为中心, 兼具多元性、层次性与差异性的特点, 让不 同层次的学生既实现共性的要求, 又达到个性的充分发展。例如以教育部最新的《高中英语 课程教学要求》制定 $\mathrm{A} 、 \mathrm{~B} 、 \mathrm{C}$ 三个层级基本目标, 又根据不同层级学生的认知水平, 详细地 量化标准和具体规定语言知识、语言技能、情感态度、学习策略、文化意识的目标, 使不同 层次的学生得到不同程度的发展。

\section{3 采用合适的教学方法}

不同层级班级的老师要善于采取不同的教学方法, 实施因材施教, 为每一类学生掌握不 同的内容提供切实有效的方法。例如 $\mathrm{A}$ 层级学生基础较差, 课堂讲授应循序渐进的原则, 适 当放慢教学进度, 并配合大量的讲解和示范, 以激发兴趣为主。对于占总人数大多数的 $\mathrm{B}$ 级 学生, 课堂上教师与学生并重, 教学进度适中, 讲问结合, 注重语言知识与技能的系统性, 
以夯实基础知识和训练基本技能为主。C 层级学生具有较好的英语基础、较强的自学能力, 教师可适当加快教学进度, 注重课外强化训练, 课堂上注重引导学生探究学习、合作学习。

\section{4 完善教学评价体系}

合理客观的教学评价对学生、高中英语教师、教学管理部门都可以起到重要的指导和反 馈作用。高中英语分层走班教学模式应注重形成性评价和终结性评价相结合, 既关注学生的 英语学习行为又关注英语学习结果, 两者的结合可作为对学生动态分层管理的重要依据。形 成性评价的方式是多种多样的, 如根据上课出勤情况、课堂纪律及学习态度、课堂上的发言 与讨论、作业完成情况给出评定。终结性评价也要体现层次性, 试卷要包含一定量的基础题、 提高题和拓展题, 不同层次的学生完成不同类别的题目。同时教师要根据不同层次学生的特 点采用不同的评价方法, 例如对 $\mathrm{A}$ 层级学生采用表扬评价为主, 及时肯定他们的进步, 使他 们消除自卑心理, 重拾英语学习的信心。对 $\mathrm{B}$ 层级的学生采用激励评价, 指出的成绩与不足, 促使他们积极向上。对于 $\mathrm{A}$ 层级的学生以竞争性评价为主, 坚持高标准严要求, 促使他们更 加发奋努力，不断进步。

《关于深化考试招生制度改革的实施意见》对于普通高中的英语教学具有重要的反拨效 应, 高中英语分层走班教学模式以提高教学质量为目标, 是新高考背景下深化普通高中课程 改革的重要内容。由于高中英语分层走班教学模式是一种大面积, 动态的组织过程, 需要在 在分层编班标准、教学目标、教学方法、教学评价体系、教学教务管理制度五个方面综合设 计, 才能适应新高考改革的需要, 使不同层级学生的英语综合应用能力都能得到充分发展。

\section{致谢}

本文为湖北省教育厅教育科学规划课题 《互联网+时代基础英语的课堂生态研究》 (2017GB080)的阶段性成果之一。

\section{References}

[1] Lishan Lv. Influence of stratified English classes in senior high school on students' affective factors. Journal of Henan Institute of Education (Philosophy and Social Sciences Edition), vol. 3, pp.133-136, 2013.

[2] C. M. Chen and Y. L. Li, Personalised context-aware ubiquitous learning system for supporting effective English vocabulary learning, Interactive Learning Environments, vol. 18, pp.341-364, 2010.

[3] Higher Education Department of the Ministry of Education, Requirements for English teaching in senior high schools, Tsinghua University Press, 2007.

[4] M. K. O'Sullivan and K. B. Dallas, A collaborative approach to implementing 21st century skills in a high school senior research class. Education Libraries, vol. 33, pp.3-9, 2017. 